\title{
Papel de KLF6, Como Factor de Predicción Precoz en Cáncer Colorrectal Humano
}

\author{
Role of KLF6 As Early Predictor in Human Colorectal Cancer \\ "Delia Laime; "Octavio Llanqui; **Francisco Sanz-Rodríguez; "*Ángeles Juarranz;

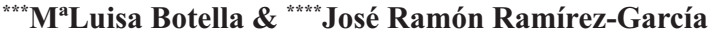

LAIME, D.; LLANQUI, O.; SANZ.RODRÍGUEZ, F.; JUARRANZ, A.; BOTELLA, M. L. \& RAMÍREZ-GARCÍA, J. R. Papel

de KLF6, como factor de predicción precoz en cáncer colorrectal humano. Int. J. Morphol., 30(3):1115-1131, 2012.

RESUMEN: El cáncer colorrectal (CCR) constituye el segundo tipo de cáncer más frecuente en la población europea. Actualmente no existe biomarcadores moleculares que se pueden utilizar para la detección temprana del cáncer de CCR. KLF6 es un supresor tumoral relacionado con varios tipos de cánceres. Nuestra hipótesis plantea que KLF6 puede ser un excelente marcador en el diagnóstico precoz de CCR. Para estudiar la implicancia de KLF6 en el CCR, se seleccionaron 15 biopsias de cada estadio (T1,T2 y T3) de los archivos del Servicio de Anatomía Patológica del Hospital Central de la Defensa Gómez-Ulla, las cuales presentaban áreas de tejido afectado (tumor) y áreas sin afectación (no tumorales). Para ello se realizó un estudio histológico, inmunohistoquímico y RT-PCR, basada en la expresión de 3 genes, Ki67 y p53 como marcadores positivos y KLF6 como marcador en estudio. Los resultados mostraron que la expresión de KLF6 está directamente relacionada con el aumento de la malignidad celular en los adenocarcinomas, corroboradas por las RT-PCR, observándose la aparición progresiva de formas de procesado alternativo, no correspondiente a KLF6. Esta proteína, se expresó tanto a nivel citoplasmático como nuclear en los primeros estadios T1 y T2, para desaparecer a nivel nuclear en el estadio más avanzado (T3). Concluimos que KLF6 es un buen marcador tumoral de CCR, debido a que muestra patrones crecientes de expresión a nivel citoplasmático y decrecientes a nivel nuclear.

PALABRAS CLAVE: KLF6; Adenocarcinoma; Cáncer de colon.

\section{INTRODUCCIÓN}

El incremento anual en la incidencia de cáncer colorrectal (CCR) en España, se redujo en los últimos años de $4,3 \%$ a $2,5 \%$ en los hombres, de igual forma en las mujeres. La tendencia de la incidencia contrasta con la mortalidad, donde las tasas de mortalidad en ambos sexos comenzó a declinar (López-Abente et al., 2010).

KLF6 pertenece a la familia de los factores de transcripción Krüppel se caracterizan por poseer dominios de unión al ADN llamados "dedos de Zinc". Es conocido que muchos KLFs juegan un papel significativo en la tumorogenesis en diferentes órganos y tejidos. Como son KLF4, KLF5 y KLF6 presentando alteraciones en los tumores del tracto gastrointestinal (Ghaleb \& Yang, 2008). Actualmente, se sabe que existe un nexo entre la alta frecuencia de pérdida de heterocigosidad y/o mutaciones de KLF6, en cáncer de próstata (Xian-feng et al., 2008) y en cáncer gastrointestinal (Ghaleb \& Yang, 2008). La inactivación de los genes supresores de tumores tiene un papel central en la patogénesis del cáncer. Una definición más funcional de los supresores tumorales dada por Haber \& Harlow (1997) también se aplica a KLF6: "son genes que sufren mutaciones, inactivando su función en cáncer". En este sentido, se han identificado mutantes de KLF6 en cáncer de próstata, a diferencia de KLF6 normal carecen de la capacidad de activar $\mathrm{p} 21$, responsable de los efectos supresores de p53 y de KLF6 (Narla et al., 2001; Reeves et al., 2004). Además, las mutaciones en los sitios de procesamiento del ARN en cáncer pueden conducir a un incremento de un producto de procesado no habitual como se ha descrito para p53 (Varley et al., 2001). Por tanto, la identificación de formas de procesado alternativo de KLF6 en tumores humanos concuerda con otros casos descritos. En el sistema de KLF6 se ha descrito la existencia de formas alternativas de proce-

\footnotetext{
* Depto. de Biología, Facultad de Ciencias, Universidad de Tarapacá, Arica, Chile.

** Depto de Citología, Facultad de Ciencias, Universidad Autónoma de Madrid, Madrid, España.

*** Centro de Investigaciones Biológicas (CIB), Centro superior de Investigaciones Científicas, (CSIC), Madrid, España.

***** Depto. de Anatomía Patológica, Hospital Central Militar “Gómez Ulla”, Madrid, España.
} 
sado del ARN mensajero del gen, que dan lugar a proteínas defectuosas en las regiones de unión al ADN (Narla et al., 2005a, 2008). Se han aislado hasta 3 variantes distintas, que difieren de la forma normal de KLF6 por poseer solo 2, $1 \mathrm{o}$ ningún dedo de Zinc, estas son las variantes 1, 2, y 3. Actualmente, se ha demostrado que KLF6-SV1, variante de splicing oncogénica del gen supresor tumoral KLF6, se sobre expresa específicamente en cánceres humanos. El incremento de la expresión de KLF6-SV1 se asocia con el mal pronóstico en cáncer de próstata, pulmón y ovario. Por otra parte, KLF6-SV1 ha demostrado ser biológicamente activo, antagónico a la función supresora de KLF6 y promueve el crecimiento tumoral en ovario y en modelos de cáncer de próstata (Difeo et al., 2008).

\section{MATERIAL Y MÉTODO}

Muestras. Se utilizó material de los archivos del Servicio de Anatomía Patológica del Hospital Central de la Defensa Gómez-Ulla. Se seleccionaron adenocarcinomas de intestino grueso, que presentaban áreas de tejido afectado (tumor) y áreas sin afectación (áreas no tumorales o adyacentes), tanto para las piezas incluidas en parafina como al fresco de las autopsias. Se seleccionaron un total de 45 muestras, 15 por cada estadio (T1; T2 y T3), según clasificación de TNM (American Joint Comite for Cancer Staining).

Obtención de las muestras tisulares. Las piezas tumorales se fijaron en formaldehído tamponado al $10 \%$ durante 24 horas. Seguidamente se deshidrataron en batería de alcoholes y posteriormente se incluyeron en parafina de acuerdo a protocolos convencionales. Se realizaron cortes de $4 \mu \mathrm{m}$, teñidos con hematoxilina-eosina, para seleccionar áreas tumorales y no tumorales.

Inmunohistoquímica. Para determinar el patrón de expresión y localización subcelular de KLF6 en las células del tejido tumoral y controles, primeramente se realizó el estudio de los factores de proliferación tumoral con anticuerpos primarios de ratón para Ki67 y p53, (Dako Corporation), y de conejo (Santa Cruz Biotecnology) para KLF6. Los anticuerpos secundarios usados anti-IgG de ratón acoplado a Alexa ${ }^{\circledR}-488$ y anti-IgG de conejo acoplado a Alexa®-488. Todos los anticuerpos se prepararon en solución comercial del anticuerpo secundario biotinilado (Multi Link Universal, BioGenex®). La inmunohistoquímica se realizó sobre secciones de tejido incluido en parafina y al fresco. El método utilizado, fue el de estreptavidina-biotina-peroxidasa (SBP), basado en la técnica de Hsu et al. (1981). Posteriormente se realizó la tinción de contraste nuclear con hematoxilina de Harris, las muestras se deshidrataron y se montaron en definitivo con resina sintética DePex.

Estudio evaluativo. La evaluación de la expresión de p53 y Ki67, se determinó por el porcentaje de núcleos en las células tumorales como en las no tumorales. Se estudiaron 10 cortes al azar de cada caso, seleccionándose 10 campos de cada sección, estimándose un total de 800-1500 núcleos, tanto en células tumorales (lesión) como las no tumorales (tejido adyacente). Se consideraron positivos todos los núcleos que presentaron reacción positiva, independientemente de la intensidad de la misma. Para KLF-6, se consideró la expresión positiva de las células tumorales y no tumorales, mediante una valoración cualitativa, según los siguientes parámetros: Nula: cuando no había expresión, Baja: cuando la expresión era menos del 33\% de las células, Moderada: cuando la expresión positiva era entre el 33 al $66 \%$ y Alta: cuando la expresión mostraba más del $66 \%$ de las células.

RT- PCR. Extracción de ARN a partir de tejido incluido en parafina. La extracción de ARN a partir de muestras incluidas en parafina se realizó utilizando el "Optimum FFPE ARN Isolation kit" (Ambion Diagnostics). Proceso iniciado con la desparafinización con xilol. Obteniéndose un sedimento seco que se sometió a digestiones sucesivas con Proteinasa K (Sigma), y purificación selectiva a través de una columna donde quedó retenido el ARN. Tras varios lavados el ARN se eluyó de la columna y se disolvió en agua (Milli-QTM). Todos los pasos de purificación se realizaron según recomendaciones del fabricante (AMBION). La extracción de ARN de los fragmentos de tumores fijados en formalina tamponada se realizó con el "RNAeasy kit" (Qiagen). El ARN se amplificó usando la transcriptasa reversa para RT-PCR (Roche). La amplificación por PCR del ADN complementario (ADNc) se realizó usando la polimerasa "Taq Hotmaster" (Eppendorf).

Extracción de ARN a partir de tejido fijado en formalina. La extracción de ARN a partir de tumores fijados en formalina se realizó con $60 \mathrm{mg}$ de tejido. Se maceró con tampón de lisis RLT del "RNAeasy kit", según recomendaciones de la casa comercial, en presencia de bmercaptoetanol 1\% (Sigma). Seguidamente se procedió a la extracción del ARN, según el protocolo, de purificando, lavando y eluyendo el ARN de las columnas del "kit". Recuperándose en un volumen de 30 microlitros de agua, libre de RNAsas y DNAsas. La concentración de ARN total, procedente de las muestras en parafina y al fresco, se valoró en un espectrofotómetro a $260 \mathrm{~nm}$.

Expresión del ARN de KLF6. Los niveles de expresión de los genes de KLF6 se determinó mediante transcripción reversa (RT) del ARN total, seguido de la amplificación del ADN complementario (ADNc) así obtenido por PCR. Para 
la RT se utilizó $1 \mu \mathrm{g}$ de ARN total, usando la transcriptasa reversa de AMV, para RT-PCR de Roche. Como cebadores se utilizó una mezcla al azar de hexanucleótidos que anillan en diversas partes a lo largo de los transcritos, siguiendo el
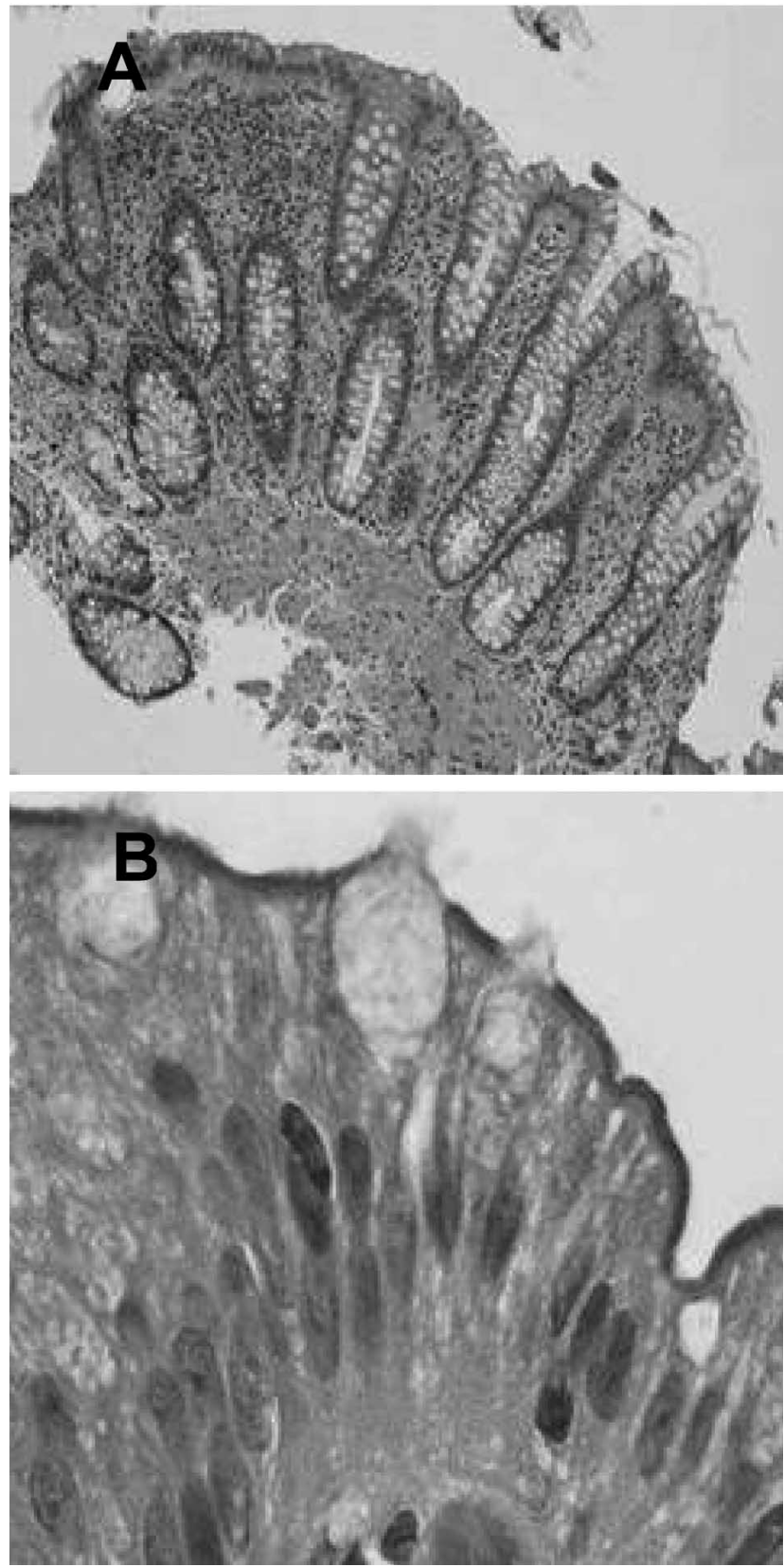

Fig. 1. Colon humano. A: Caso control de colon que incluye la mucosa y la submucosa. Se observa el epitelio de revestimiento y glándulas intestinales con predominio de células caliciformes y la lámina propia que contiene una variable cantidad de células inmunocompetentes (X40). B: Detalle de la mucosa intestinal del caso control anterior (flecha en A) en el que se aprecia el epitelio de revestimiento constituido por abundantes enterocitos y células caliciformes. Los enterocitos presentan un marcado ribete estriado y núcleos elongados, isomórficos, de cromatina laxa y nucleolos de pequeñas dimensiones (X1000). H-E. protocolo indicado por Roche. La amplificación por PCR del ADNc se realizó usando la polimerasa "Taq, Hotmaster" (Eppendorf), en $200 \mathrm{ml}$ de una mezcla de desoxinucleótidos tri-fosfato (dNTPs) y las siguientes parejas de oligonucleótidos: a.- Para las diferentes variantes de procesado de KLF6: KLF6 salvaje "Forward": 5'-CGG ACG CAC ACA GGA GAA AA-3'; KLF6 salvaje "Reverse": 5'CGG TGT GCT TTC GGA AGT G-3' y KLF6 total "Forward": 5'-CTG CCG TCT CTG GAG GAG T-3'; KLF6 total "Reverse": 5'-TCC ACA GAT CTT CCT GGC TGT C-3'. El tamaño esperado para la amplificación de KLF6 salvaje fue de $112 \mathrm{pb}$, mientras que para la amplificación total de KLF6, es de 99 pb. b.- Como control endógeno se utilizó la Guanin Adenosil Fosfato deshidrogenada (GAPDH): GAPDH "Forward": 5'-CAA TGA CCC CTT CAT TGA CC-3' y GAPDH "Reverse": 5'-GAT CTC GCT CCT GGA AGA TG-3'. El tamaño del producto de la PCR de GAPDH fue de $400 \mathrm{pb}$.

La PCR se inició con la desnaturalización del ADN a $95^{\circ} \mathrm{C}$ durante $2 \mathrm{~min}$. Seguidamente, se realizaron 35 ciclos: Desnaturalización a $95^{\circ} \mathrm{C}$ durante $30 \mathrm{seg}$, anillamiento a 52 ${ }^{\circ} \mathrm{C}$ durante $30 \mathrm{seg}$ y elongación a $68^{\circ} \mathrm{C}$ durante $45 \mathrm{seg}$. La PCR finalizó con la elongación a $68^{\circ} \mathrm{C}$ durante $7 \mathrm{~min}$, seguido de un enfriamiento a $4^{\circ} \mathrm{C}$. Los fragmentos de ADN amplificado se separaron en geles de Agarosa, al 5\%, y se tiñeron con bromuro de etidio $(10 \mathrm{mg} / \mathrm{ml})$, se fotografiaron en un transiluminador de ultravioleta (UV) con cámara.

\section{RESULTADOS}

Histopatología. El caso control presentó un epitelio cilíndrico simple con enterocitos de citoplasma amplio y claro con numerosas células caliciformes. Una lámina propia constituida por un tejido conjuntivo y musculatura lisa (Fig. 1AB). En los adenocarcinomas (Fig. 2). En el estadío T1 se observó una neoformación de estirpe epitelial y diferenciación glandular que estaba constituida, en la mayoría de los casos, por luces glandulares de diferente talla y morfología. Las glándulas se encuentran revestidas por un epitelio cilíndrico pseudoestratificado de células con citoplasma amplio eosinófilo y núcleo pleomórfico con nucléolo prominente y con escasa o ninguna vacuola de mucosecreción (Fig. 2AB). Dichas luces glandulares se asientan sobre un estroma de tejido conjuntivo fibroso que, de manera general, muestra infiltrado inflamatorio de tipo crónico inespecífico y focos de sufusión hemorrágica estadío T2 (Fig. 2C-D). En determinadas áreas, el carcinoma se muestra más indiferenciado con luces glandulares irregulares, observándose núcleos con gran atipia, pleomorfismo y nucléolo prominente en el estadío T3 (Fig. 2E-F). 

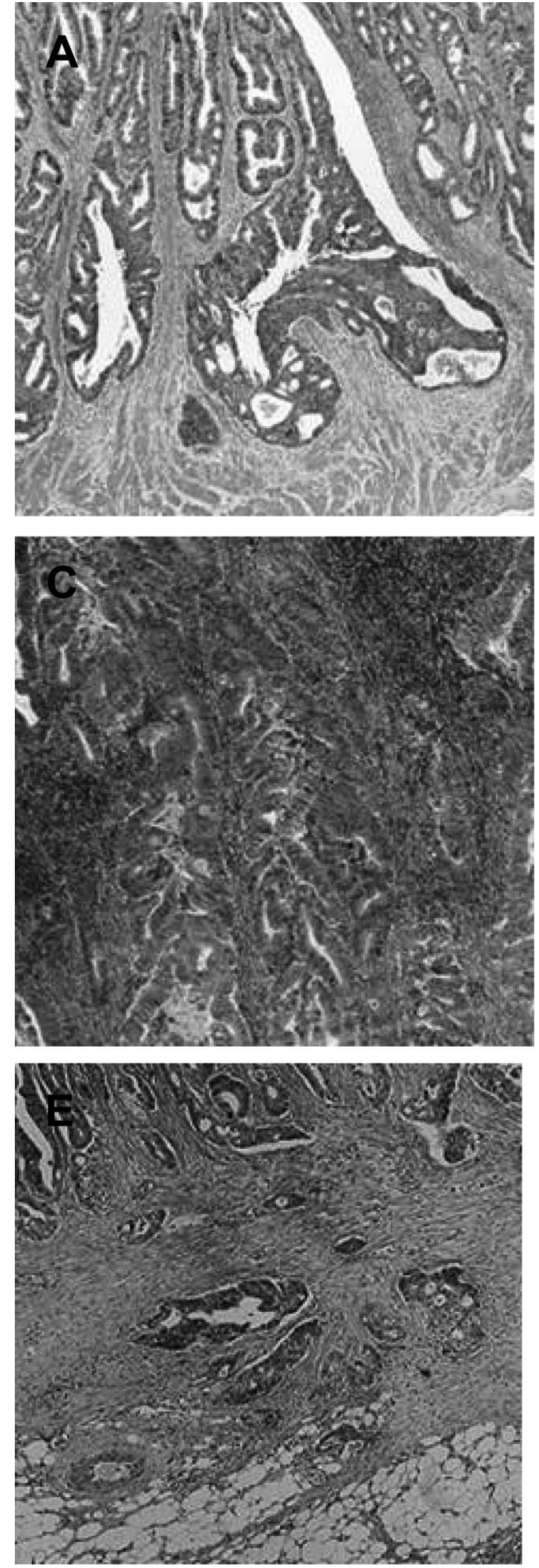
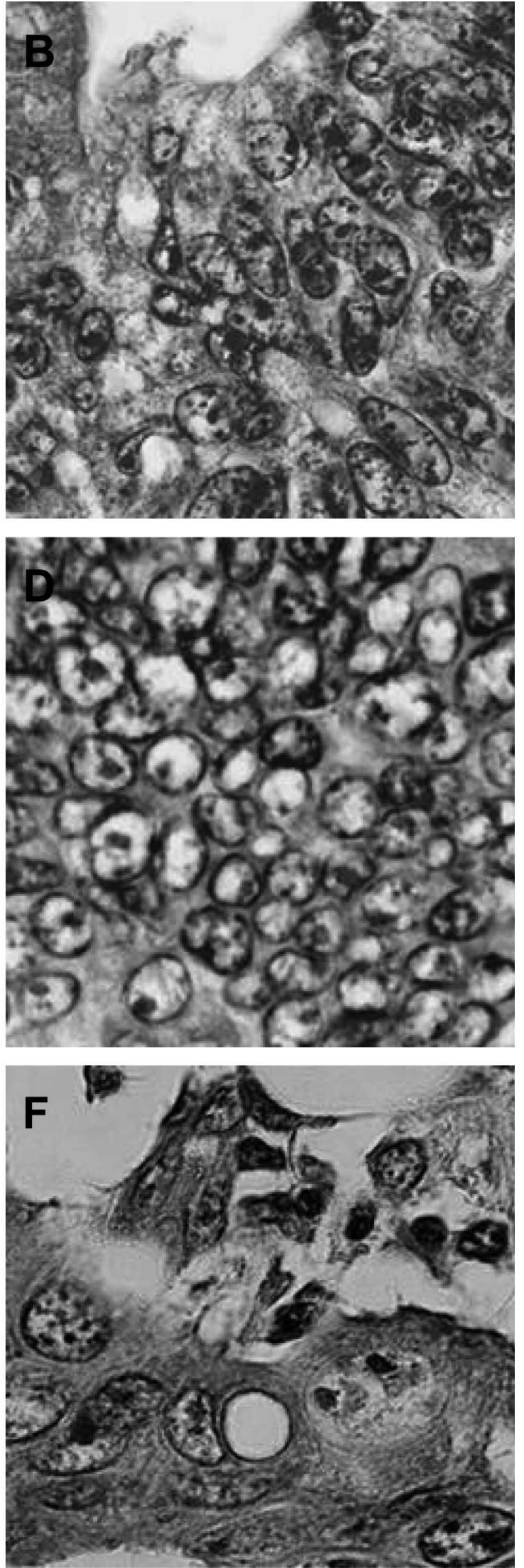
Inmunohistoquímica. Factor de proliferación Ki67: En los controles se observó una leve inmunotinción para Ki67 en las células basales, fundamentalmente en el fondo de las criptas de Lieberkhün (Fig. 3A-B). Por el contrario se de-
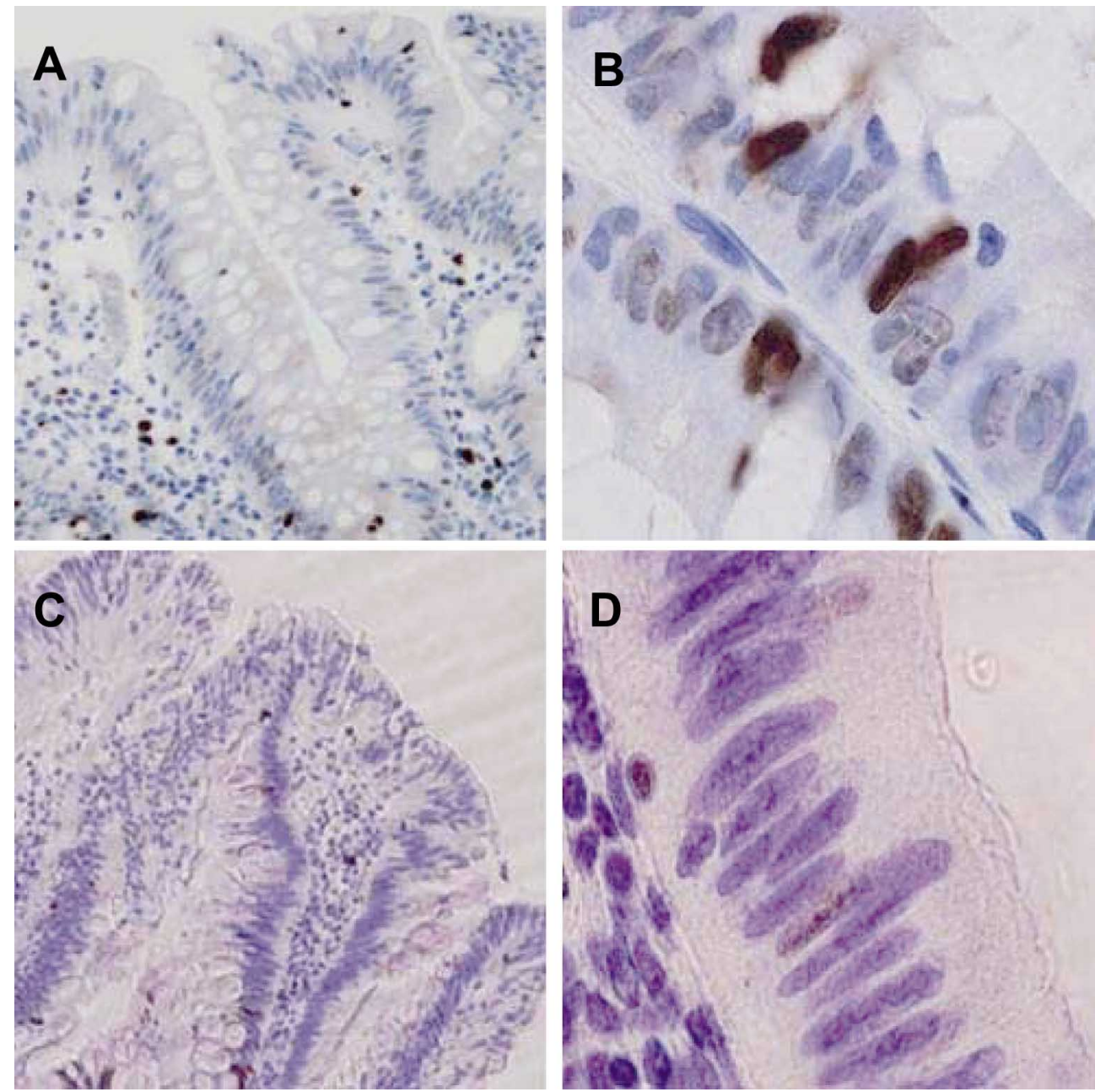

Fig. 3. Controles de colon humano. Expresión de Ki67 y de p53 en epitelio de colon de un caso control. A: Epitelio intestinal con escasas células positivas a Ki67 (expresión nuclear), las cuales se disponen en el fondo de las criptas de Lieberkhün (X100). B: Detalle de las criptas glandulares con células Ki67 positivas (X1000). C: Imagen panorámica de la mucosa de intestino grueso normal con escasa expresión de p53, sólo en algunos de los núcleos de los enterocitos (X100).D: Detalle del epitelio que muestra las células de colon carentes de expresión de p53 (X1000).

Fig. 2. Página 1118. Adenocarcinoma de colon. A: Adenocarcinoma diferenciado estadio T1. Se observan abundantes glándulas distribuidas irregularmente, con áreas sólidas focales. Las células tumorales presentan moderada diferenciación mucosecretora (X40). B: Muestra detalles de las células epiteliales malignas pobremente diferenciadas con intenso pleomorfismo nuclear (X1000). C: Tejido pobremente diferenciado, estadio T2 en el que se observan escasas formaciones glandulares. El intersticio es escaso y contiene abundantes vasos sanguíneos y focos hemorrágicos (X40). D: Detalle de células epiteliales desdiferenciadas con citoplasma escaso y sin diferenciación mucosecretora. Los núcleos son pleomórficos y los nucleolos son de grandes dimensiones (X1000). E: Adenocarcinoma estadio T3, indiferenciado que penetra ampliamente en la submucosa, muscular intestinal, alcanzando la serosa. Las glándulas tumorales presentan núcleos pseudoestratificados, hipercromáticos y escasa diferenciación del citoplasma con mínima formación de vacuolas mucosecretoras. En la lámina propia se observan abundantes acumulos de tejido linfoide (X40). F: Se eviencian células tumorales indiferenciadas, donde se aprecian células epiteliales con núcleos pleomórficos (X1000).H/E. 
LAIME, D.; LLANQUI, O.; SANZ.RODRíGUEZ, F.; JUARRANZ, A.; BOTELLA, M. L. \& RAMíREZ-GARCíA, J. R. Papel de KLF6, como factor de predicción precoz en cáncer colorrectal humano. Int. J. Morphol., 30(3):1115-1131, 2012.

tectó inmunorreactividad para Ki67 en los carcinomas, observándose mayor expresión del marcador en los núcleos de las células. No se observó una relación directa entre pleomorfismo nuclear y la mayor expresión de Ki67, en los diferentes estadíos (Fig. 4A-F).
Proteína p53. Se observó escasa expresión de la proteína p53 de manera ocasional en algún núcleo de los enterocitos de los casos controles (Fig. 3C-D). En los adenocarcinoma, en los estadios T1 y T2, la expresión de p53 fue alta (Fig. 5A-D), observándose una disminución de la expresión en
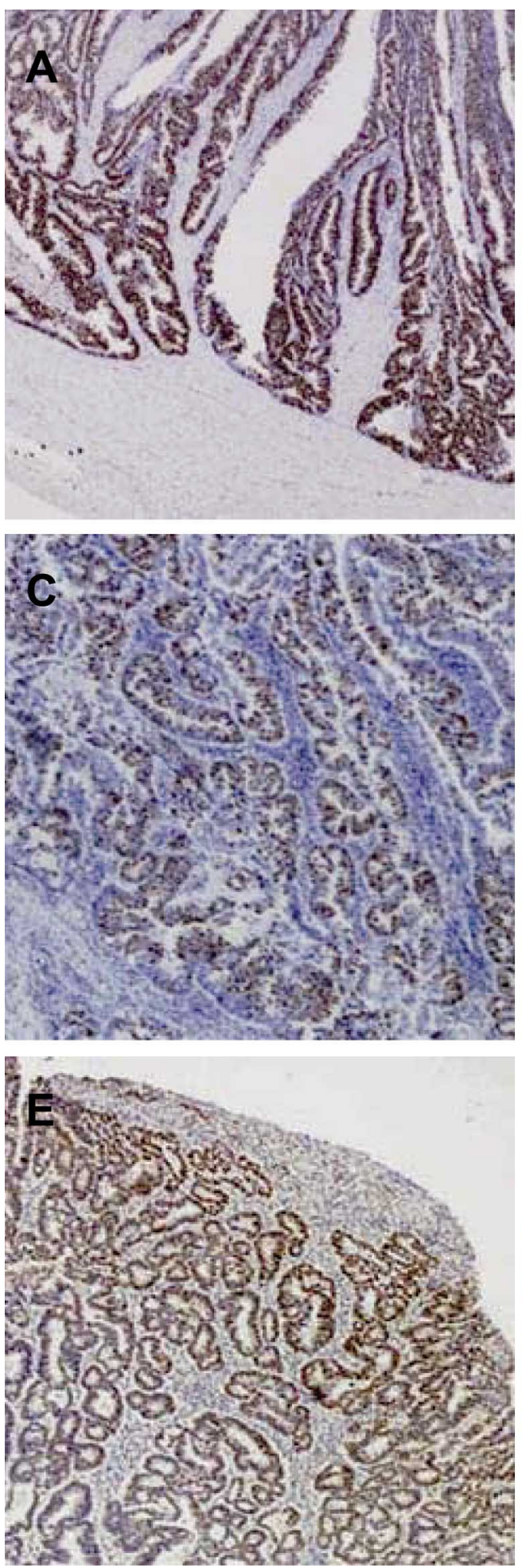
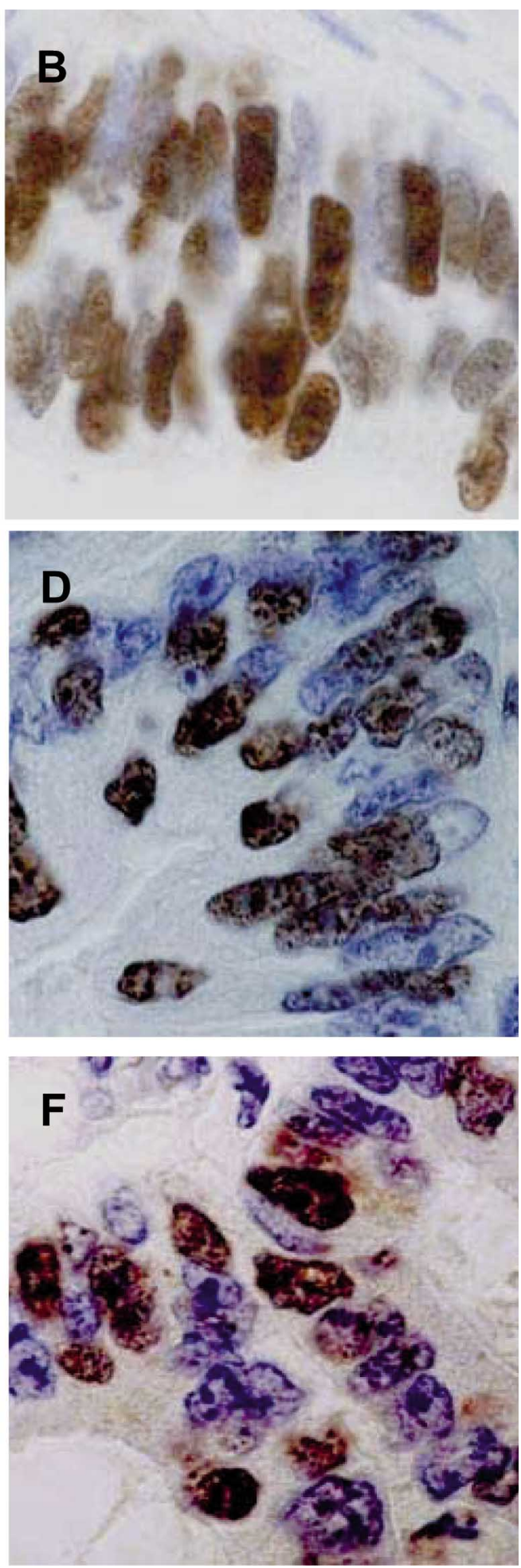

Fig. 4. Expresión de Ki67 en adenocarcinoma de colon humano.

A: Adenocarcinoma bien diferenciado de patrón papilar que infiltra focalmente la submucosa intestinal en estadio T1. El epitelio muestra numerosos núcleos Ki67 positi$\operatorname{vos}(\mathrm{X} 40)$.

B: Detalle de la imagen anterior mostrando el epitelio psudoestratificado, núcleos pleomórficos, la mayoría de los cuales son positiva para Ki67 (X1000).

C: Imagen panorámica de un adenocarcinoma moderadamente diferenciado e infiltrante en la pared muscular, que muestra glándulas muy irregulares. Se observa que la tinción nuclear de Ki67 es muy variable (X40).

D: Detalles de la imagen anterior mostrando que no existe una relación directa entre el pleomorfismo nuclear y la mayor expresión de Ki67 en estadio T2 (X1000).

E: Imagen panorámica de un adenocarcinoma bien diferenciado, constituido por glándulas proliferantes con escasa lámina propia circundante que llega hasta la profundidad de la muscular propia (X40).

F: Detalle de la figura anterior en el que alternan células epiteliales malignas Ki67 positivas y negativas. Destacan células muy pleomórficas con núcleos irregulares, de aspecto moruliforme negativos para Ki67en estadio T3 (X1000). 
estadios más avanzados (T3), en los que se expresa tan solo en el núcleo de algunas células tumorales (Fig. 5E-F).

Supresor Tumoral KLF-6. Se observó una leve expresión de KLF-6 en las células glandulares normales, tanto en el núcleo como en el citoplasma (Fig. 6 A-B). En los adenocarcinomas hay mayor expresión citoplasmática a medida que aumenta la agresividad e invasión tumoral, en especial en la superficie del epitelio glandular, no observándose expresión a nivel nuclear en el estadío T3 (Fig. 7 A-F).
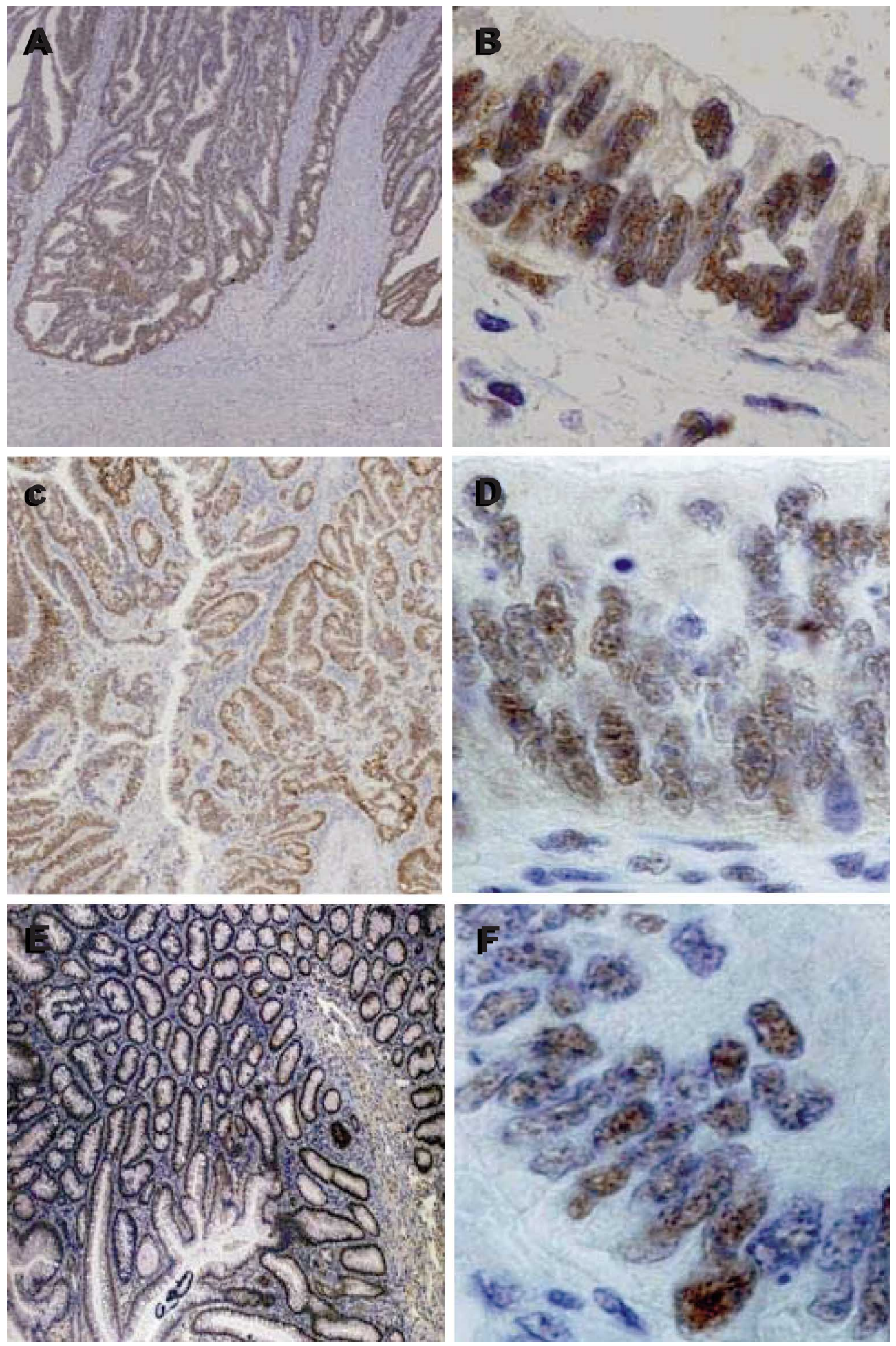

Fig. 5. Expresión de p53 en adenocarcinoma de colon humano.

A: Se observa una proliferación glandular maligna bien diferenciada que penetra en la submucosa colónica (X40).

B: Detalle de glándulas tumorales formada por un epitelio pseudoestratificado con células de tipo enteroide y una elevada positividad de p53 en las células proliferantes. En el estroma adyacente se observan algunos fibrobastos positivos a p53, en estadio T1. (X1000).

C: Imagen de colon moderadamente diferenciado que presenta una proliferación de glándulas muy irregulares con evidente marcaje de p53 (X40).

D: Detalle de células con núcleos pleomórficos, de gran tamaño y tenue marcaje de p53, estadio T2 (X1000).

E: Imagen de adenocarcinoma bien diferenciado que, sin embargo, llega a infiltrar la capa muscular externa del colon y penetra puntualmente en la serosa peritoneal. Presencia de glándulas muy irregulares con positividad para p53 (X40).

F: Detalle del epitelio glandular constituido por células desdiferenciadas con núcleos muy irregulares y de gran tamaño. p53 se expresa en la mayoría de las células tumorales y las células negativas muestran vestigios de inmunomarcaje. Los núcleos son pleomórficos, estadio T3. (X1000). 

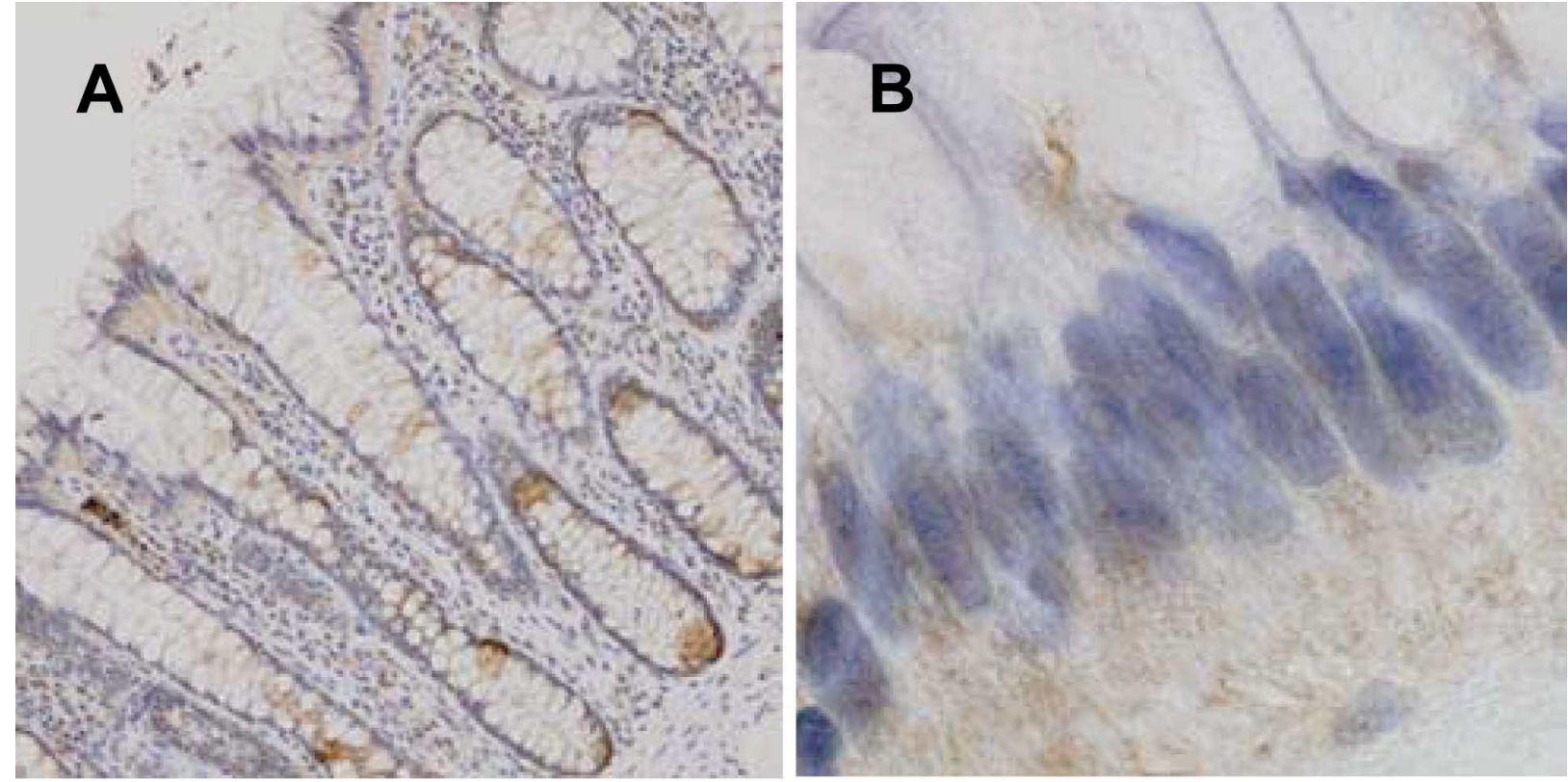

Fig. 6. Expresión de KLF6 en colon humano control. A: Imagen panorámica de la mucosa de colon. La inmunoexpresión de KLF6 aparentemente es mayor en el fondo de las criptas de Lieberkhün con respecto al epitelio superficial y el de los conductos glandulares (X40). B: Se observa la expresión de KLF6, tanto en la zona nuclear como en el citoplasma de las células epiteliales intestinales. No se observa expresión de KLF6 en las células mucosecretoras (X1000).

PCR. Supresor Tumoral KLF-6. En la figura 8 se observa la predominancia de formas normales (salvajes) en el epitelio normal de colon humano control (A). Esta situación cambia en los adenocarcinomas (Fig. 9). Se observó la aparición progresiva de las formas de procesado alternativo, provocando un aumentando la cantidad del amplificado total (salvaje+variantes) con respecto al salvaje, como se observó en T1 (Fig. 9A). En T2 se visualizó un aumento en la expresión de KLF6, al tiempo que aparecieron bandas más pequeñas al tamaño esperado para el amplicón total (Fig. 9 B). En T3, se observó una predominancia total de las formas alternativas, y no se obtuvo amplificación de la forma salvaje de KLF6 (Fig. 9C).

Caracterización de Ki67. Las diferencias observadas en las lesiones no son tan evidentes en los tejidos adyacentes controles, donde los valores de este marcador son prácticamente iguales. Basado en un análisis, paramétrico, se pudo concluir que las diferencias de expresión de Ki67 sólo son significativas en el tejido tumoral (lesión) (Fig. 10A-B). La expresión de Ki67 en la lesión y en el tejido adyacente (sano) según los test estadísticos, T de student y Wilcoxon, demostraron que las diferencias de expresión de Ki67 entre tejido sano y tejido tumoral fueron significativas en todos los esta$\operatorname{dios}(\mathrm{p} \leq 0,05$, para ambos test).

Caracterización de p53. En el tejido tumoral (lesión), p53 presenta valores de expresión muy elevados. Además, en los estadios T1 y T2, la mayor parte de los valores están muy próximos a la mediana. Sin embargo, tal y como se observa en los gráficos de Box Wiskers, los niveles de expresión, son muy altos (Fig. 11A-B). El resultado $\mathrm{T}$ de student y de Wilcoxon, demostraron que las diferencias de expresión de p53 entre tejido control (sano) $y$ el tejido tumoral fueron significativos $(\mathrm{p} \leq 0,05$ para ambos test) en todos los estadios, de los adenocarcinomas (Tabla I).

Caracterización de KLF6. En los gráficos de Box Whisker, se puede apreciar que la expresión de KLF6 es mayor en el tejido tumoral (lesión) (Fig. 12A-B). El test de MannWhitney-Wilcoxon, demostró que la expresión de KLF6 es más elevado en el tejido tumoral (lesión) que en el tejido control (sano).

\section{Análisis de la RT-PCR}

Expresión de KLF-6. En los controles, se observó una expresión moderada (Fig. 8A). Observándose la predominancia de las formas normales (salvajes) (A). No obstante, esta situación cambia al analizar las muestras afectadas de adenocarcinoma (Fig. 9A-B). Se observó la aparición progresiva de las formas de procesado alternativo, lo que produjo un aumento en la cantidad del amplificado total 

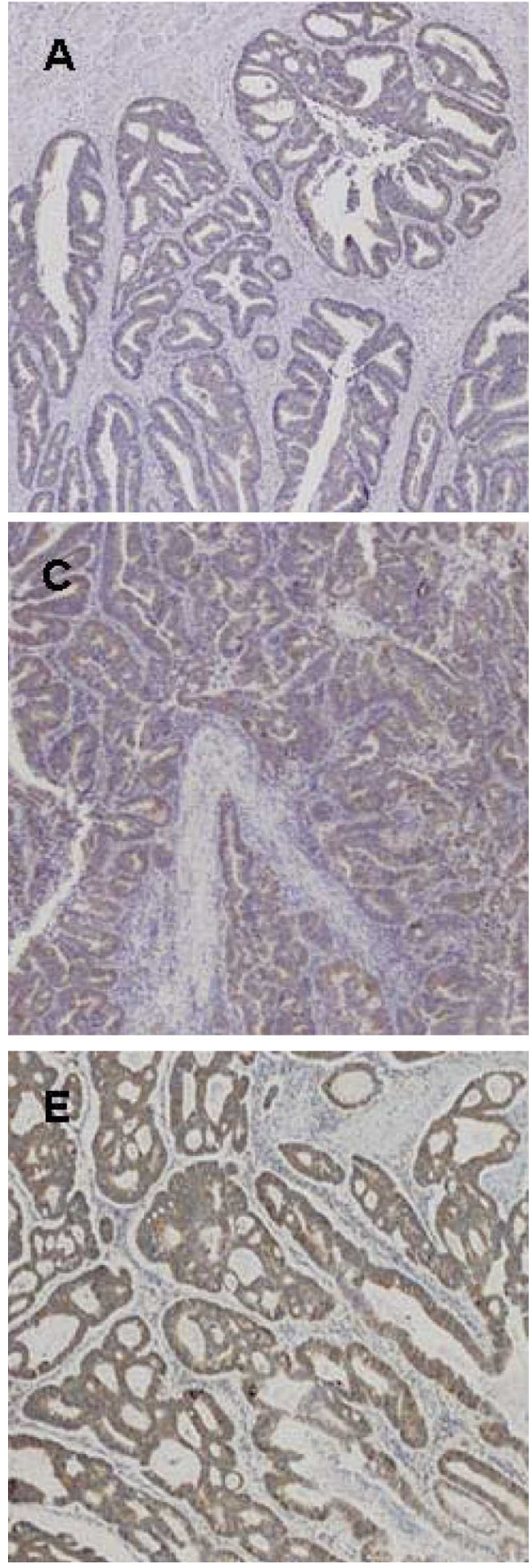
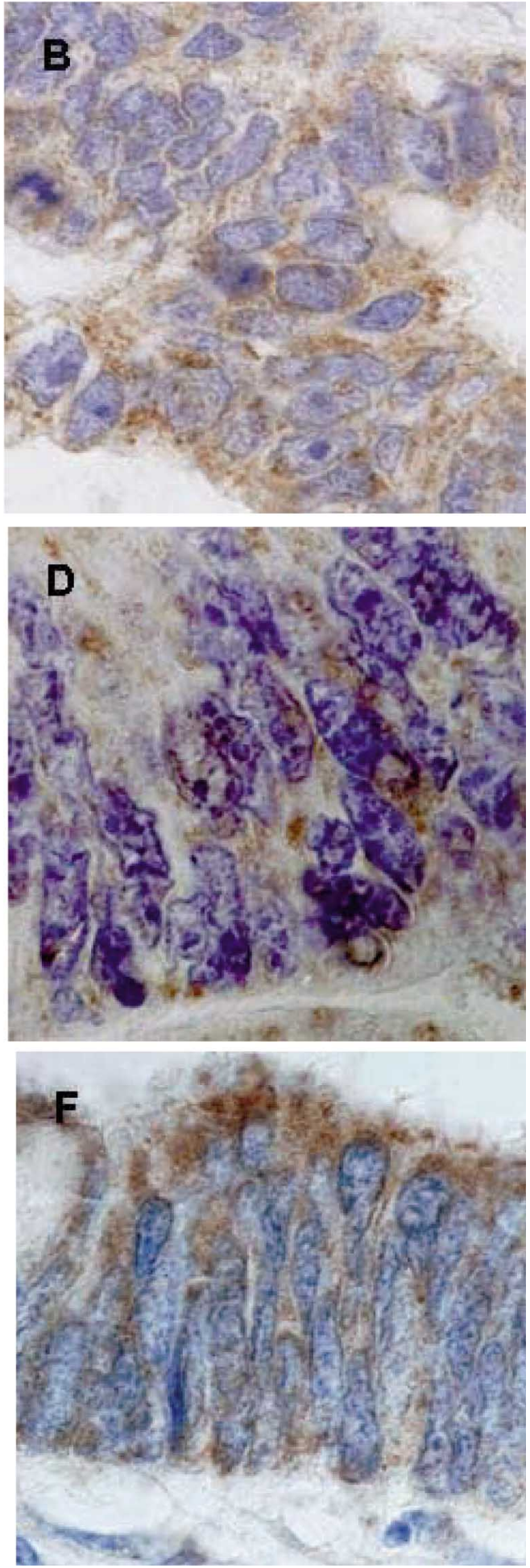

Fig. 7. Expresión de KLF6 en adenocarcinomas de colon humano.

A: adenocarcinoma bien diferenciado de colon caracterizado por la presencia de glándulas irregulares infiltrantes (X40).

B: Detalle del epitelio tumoral con abundante pseudoestratificación celular e intenso marcaje de KLF6 en la superficie del epitelio glandular, con vestigios de inmunotinción en el núcleo, estadio T1 (X1000).

C: Las glándulas infiltrantes son irregulares y presentan un evidente inmunomarcaje citoplasmático de KLF6 (X40).

D: Detalle de las células epiteliales malignas distribuidas difusamente, con glándulas irregulares de variable expresión de KLF6 en el citoplasma perinuclear. Los núcleos son hipercromáticos y aparentemente carecen de inmunotinción para KLF6, estadio T2 (X1000).

E: Se observan formaciones glandulares muy irregulares que alternan con áreas tumorales sólidas. Las células presentan variable expresión de KLF6 (X40).

F: Detalle de las células desdiferenciadas con escaso citoplasma y mínima expresión de KLF6. Los núcleos son KLF6 negativos, estadio T3. (X1000). (salvaje+variantes) con respecto al salvaje, como se observó en el estadio T1 (Fig. 9-B). En el estadio T2 se determinó un aumento en la expresión de KLF6, al tiempo que aparecieron bandas más pequeñas al tamaño esperado para el amplicón total. En el estadio T3, se observó una predominancia total de las formas de procesado alternativo (KLF6-SV1), ya que no se obtuvo la amplificación de la forma salvaje de KLF6 (Fig 9-C). 


\section{A Controles}

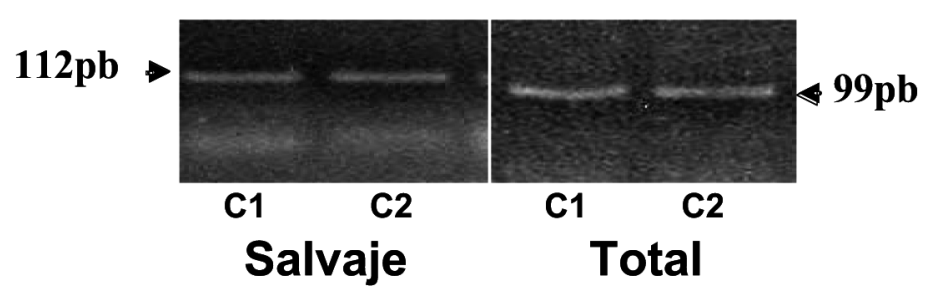

Fig. 8. PCR de KLF6: Colon humano control. Expresión de los ARNs normales (salvajes) y totales (salvaje+ formas alternativas de procesado) en epitelio sano de colon (A). Los ARN transcritos tienen un tamaño de $112 \mathrm{pb}$ en el caso de la forma salvaje de KLF6, y de 99 pb en el caso del amplicon total.

A Estadio T1

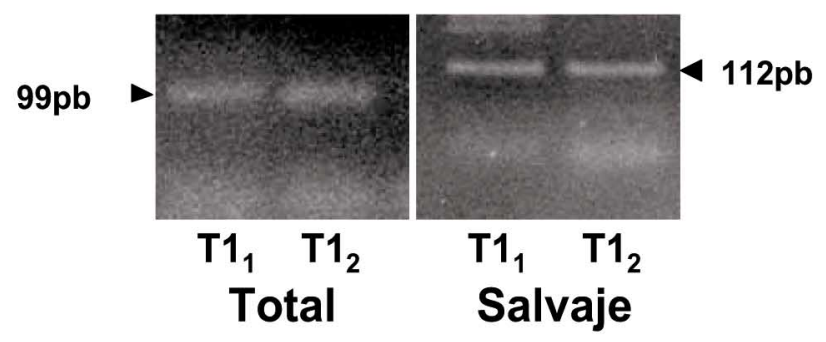

B $\quad$ Estadio T2

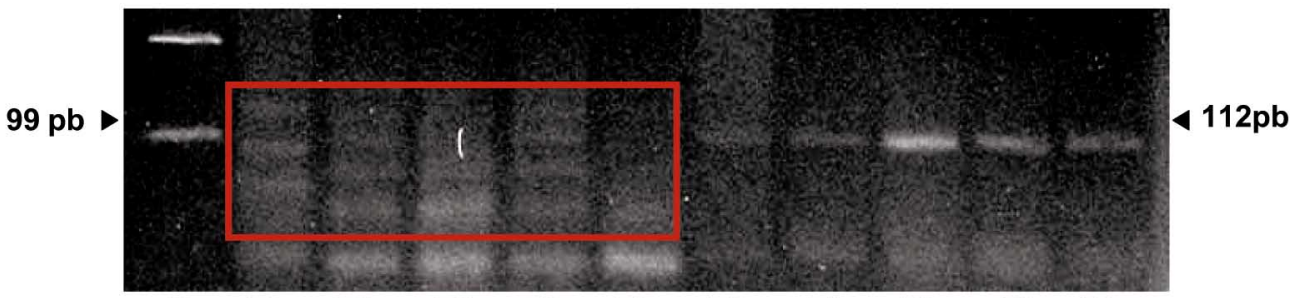

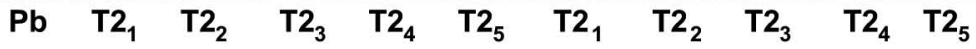
Total

Salvaje

\section{Estadio T3}

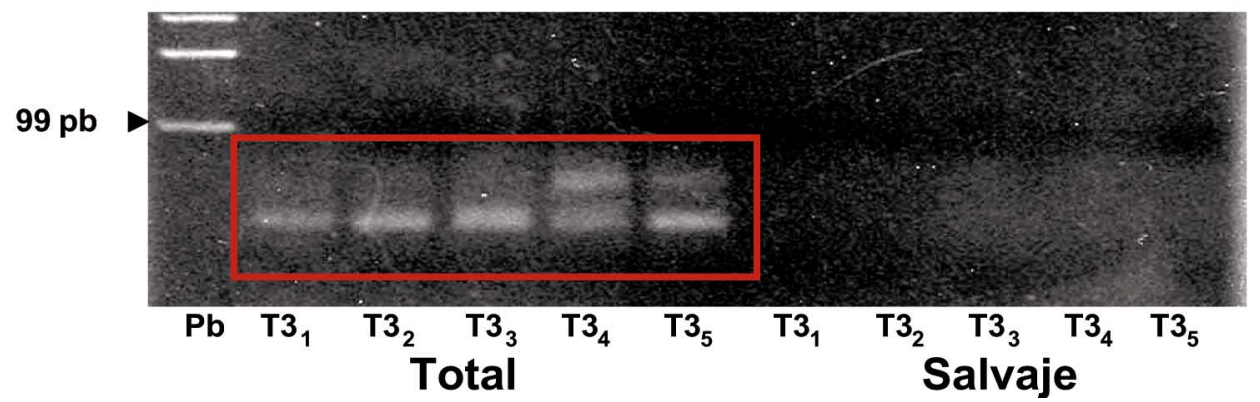

Fig. 9. PCR de KLF6 en adenocarcinomas. La expresión de ARNs mensajeros de KLF6 en muestras de adenocarcinoma de colon humano. En A se observan bandas de $112 \mathrm{pb}$ (forma salvaje) y de $99 \mathrm{pb}$ (Total) estadio T1 . En B a medida que el proceso de carcinogénesis avanza, se detecta un predominio de formas alternativas de los transcritos de KLF6 (encuadrados en rojo). Estas formas no solo aparecen como bandas de $99 \mathrm{pb}$, sino como bandas de tamaños Inferiores debido a la aparición de formas anómalas, estadio T2 . En C no se detectan bandas correspondientes al transcrito normal de KLF6 (Salvaje), sin embargo sí detectamos bandas de amplificación de las formas de procesado alternativo, estadio T3. Pb patrón de tamaño del ADN. T1, T2 o T3 hace referencia a muestras de diferentes estadios de adenocarcinoma. 

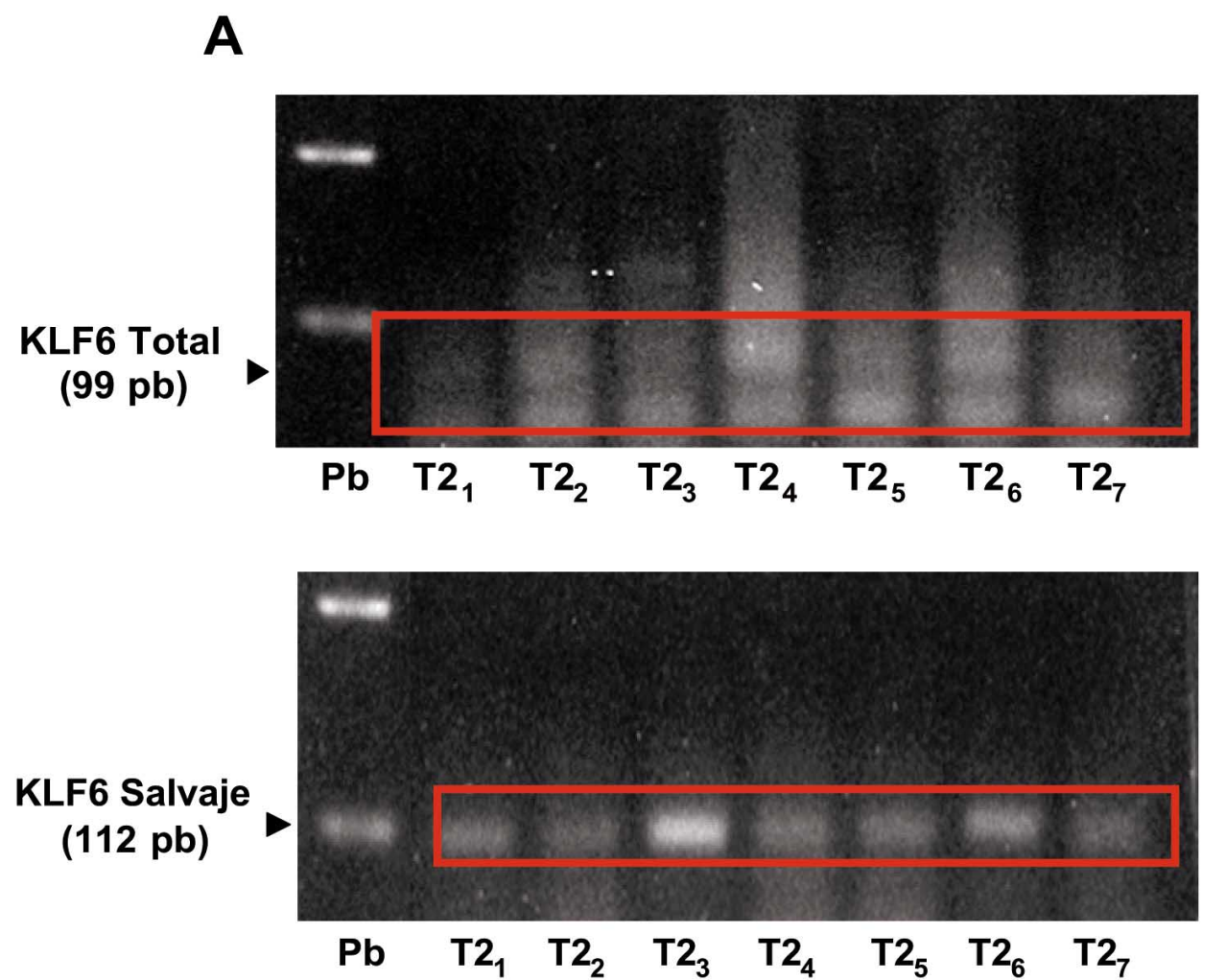

B

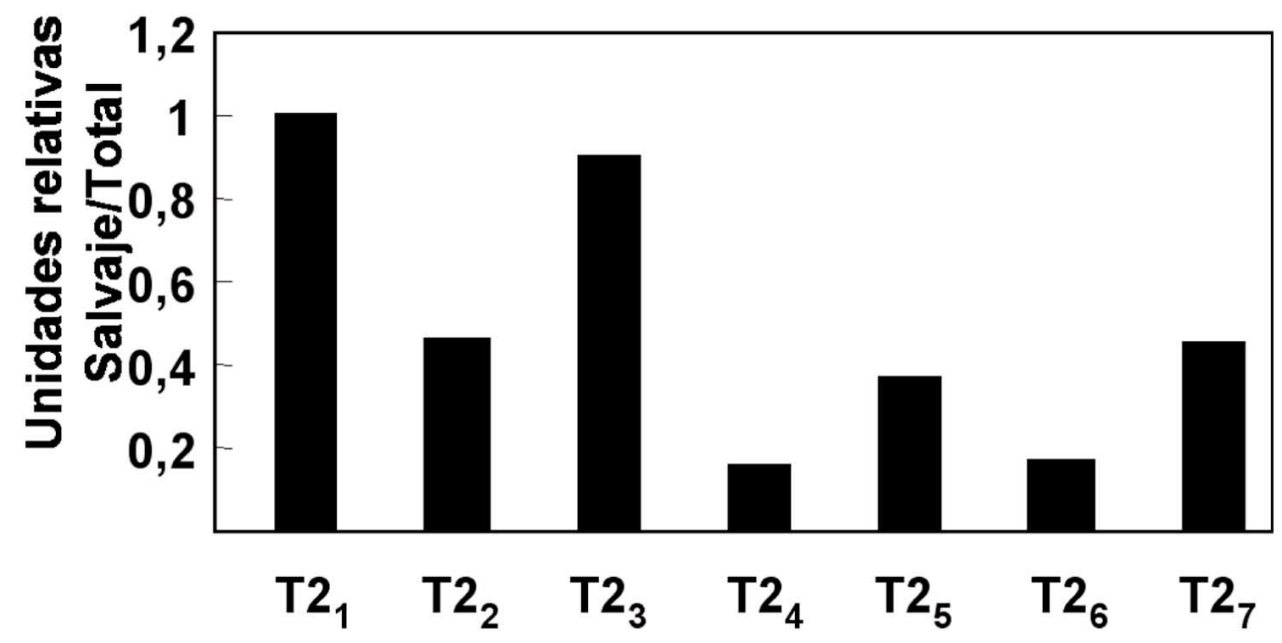

Fig. 10. PCR del ARNm de KLF6 y la relación entre la forma salvaje y las formas de procesado alternativo en muestras de adenocarcinoma de colon en estadio T2. En (A) los transcritos correspondientes al ARNm salvaje de KLF6 tienen un tamaño de 112 pb mientras que el amplicón total tiene un tamaño de 99 pb. En (B) se muestra una cuantificación del grado de procesamiento alternativo de KLF6 en este estadio T2. Se representa el cociente de los valores obtenidos por densitometría de las formas salvaje y las totales. Un cociente igual a 1 indica procesado normal del transcrito de KLF6. Sin embargo cuanto menor sea el cociente mayor será el grado de aparición de formas de procesado alternativo. El recuadro rojo indica las bandas de amplificación consideradas para la densitometría. T21-T27 muestras de distintos tumores. Pb patrón de tamaño de ADN usado. 

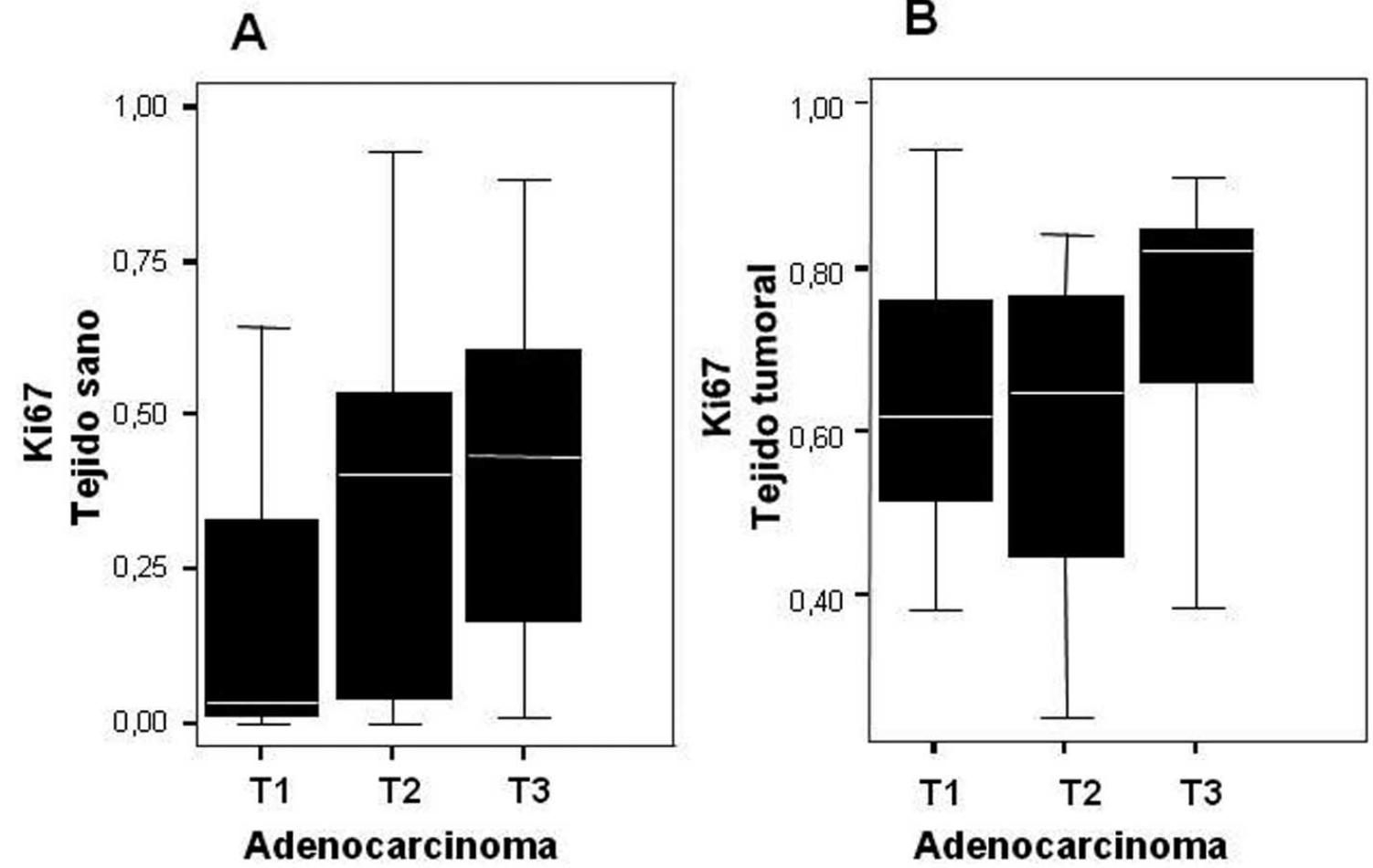

Fig. 1. Gráficos de Box Whiskers: Muestra la variación de la expresión de Ki67 en los casos de adenocarcinoma. (A) Tejido sano y (B) Tejido tumoral. T: adenocarcinoma (estadios, 1, 2 y 3).
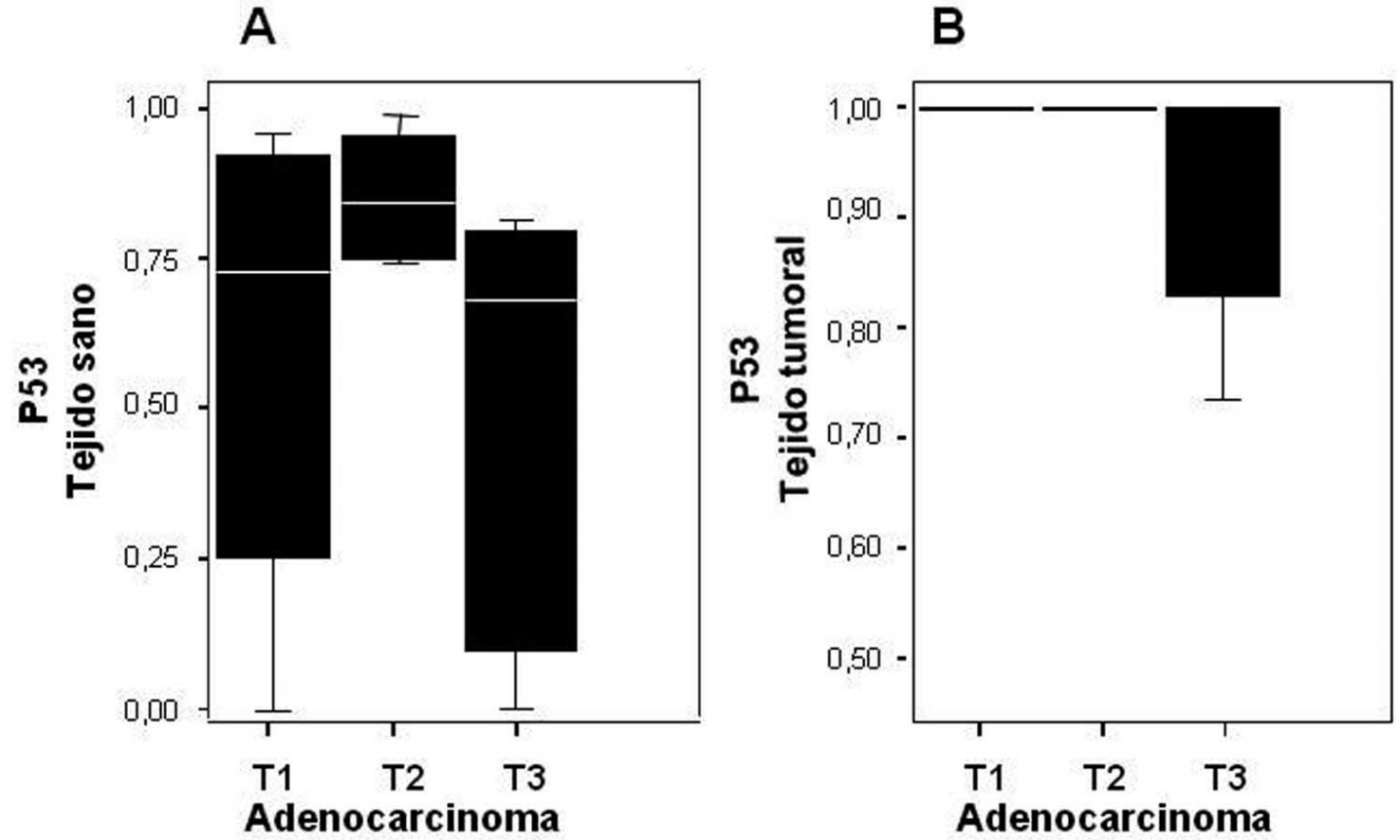

Fig. 12. Gráficos de Box Whiskers: Muestra la variación en la expresión de p53 en los casos de adenocarcinoma estudiados. Tejido sano (A) y en tejido tumoral (B). T: adenocarcinoma (estadios, 1, 2 y 3 ). 

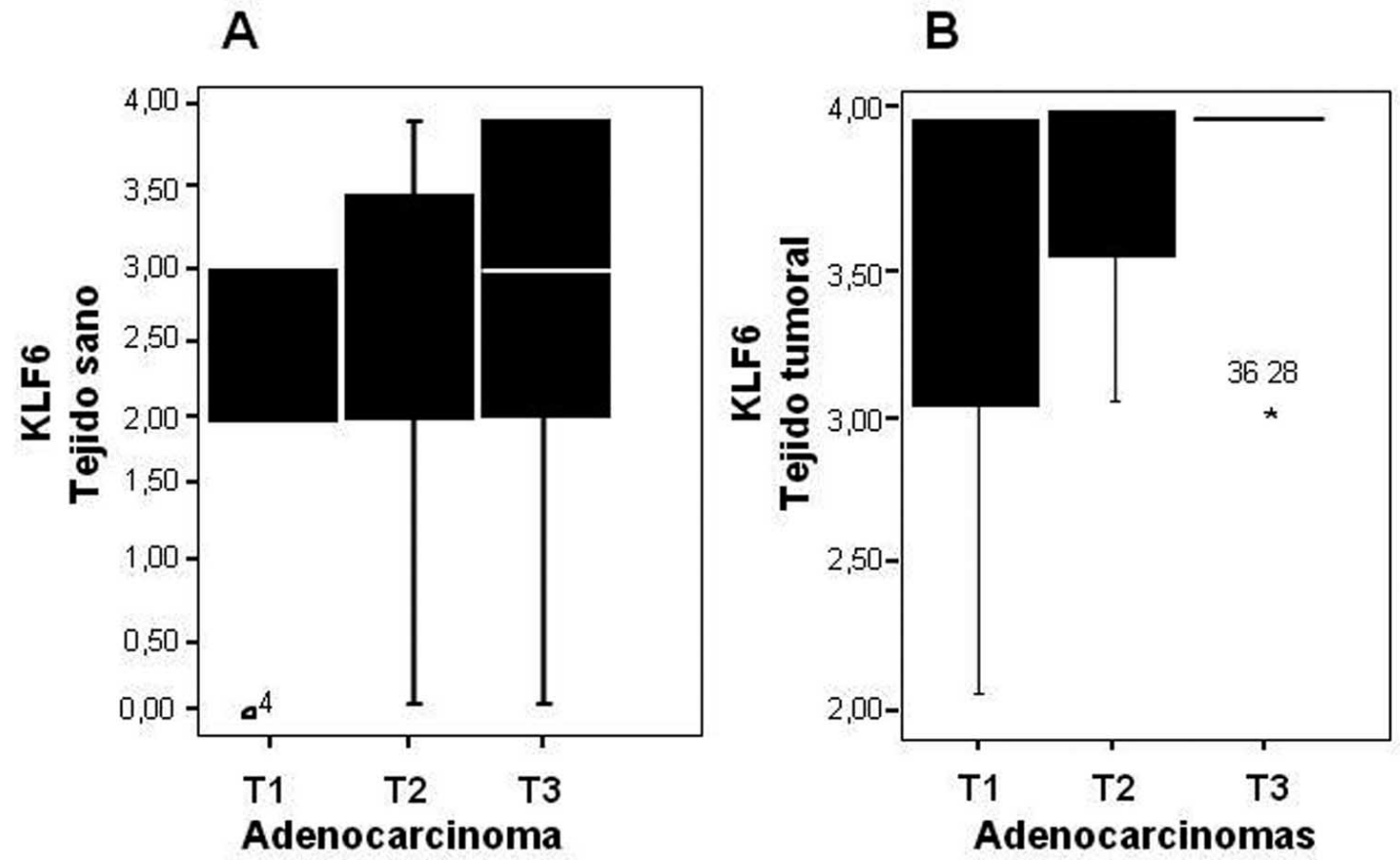

Fig. 13. Gráficos de Box Whiskers: Muestra la variación en la expresión de KLF6 en los casos de adenocarcinoma estudiados. (A) Tejido sano y tejido tumoral (B). T: adenocarcinoma (estadios, 1, 2 y 3).

\section{DISCUSIÓN}

La utilización de marcadores celulares y moleculares implicados en la progresión del cáncer de colon, permitiría comprender los procesos celulares responsables de la progresión del cáncer. Es importante predecir un diagnóstico precoz no sólo para el diagnóstico y pronóstico de los resultados del tratamiento, sino también en el posible desarrollo de nuevas estrategias o terapias dirigidas específicamente sobre los factores responsables de la invasividad del cáncer. Uno de los papeles fundamentales que llevan a cabo la familia de factores de transcripción de los KLFs, son los procesos fisiológicos y patológicos, como el crecimiento celular, tumorigenicidad, el metabolismo, la inflamación y remodelación tisular en respuesta a estrés externo (Nagai et al., 2009). Un miembro de esta familia, KLF6 ha sido identificado como un gen supresor de tumores en diferentes tipos de cáncer. En particular, se hadescrito que inhibe la proliferación, promueve la apoptosis y está implicado en metástasis, por lo que participa activamente en cáncer (Buendía et al., 2007).

La pérdida de heterocigosidad (LOH) de este gen se encuentra en múltiples cánceres, incluidos los de colon, pulmón, hepatocelular, carcinomas de ovario (Cho et al., 2006;
Narla et al. 2007; Watanabe et al., 2008). Asimismo, KLF6 es transcripcionalmente silenciado en células de cáncer esofágico mediante la hipermetilación de su promotor (Yamashita et al., 2002) y es inhibido significativamente en muestras de cáncer de pulmón en estadios muy tempranos (Kettunen et al., 2004; Ito et al., 2004), y de cáncer hepático (Kremer-Tal et al., 2007). Debido a los estudios llevados a cabo sobre el posible papel de KLF6 en cáncer, se ha sugerido que las vías complementarias por las que este supresor tumoral es capaz de regular el desarrollo y la progresión del cáncer de próstata son dos: La primera, una disminución en la expresión de la proteína salvaje de KLF6 que daría lugar a un aumento en la proliferación y tumorogenicidad in vivo. Este hecho permite correlacionar una disminución en la expresión de esta proteína con un mal pronóstico, descrito para cánceres de pulmón y de próstata (Glinsky et al., 2004; Kettunen et al., 2004). La segunda, consiste en un aumento de las formas de procesamiento alternativo. Este es un mecanismo crucial para la obtención de una diversidad proteica, a partir de un solo gen y un solo ARN mensajero. Las diferentes isoformas de procesamiento alternativo de una proteína, pueden mostrar efectos biológicos diferentes, como los efectos antagónicos. En los resultados obtenidos mediante 
inmunohistoquímica sobre expresión de la proteína de KLF6 en los diferentes estadios del CCR, se observó un incremento progresivo en la expresión de esta proteína, a medida que aumentaba la malignidad de la lesión en adenocarcinomas.

El análisis estadístico de los datos obtenidos por inmunohistoquímica en los tumores, revelaron que este aumento de expresión de KLF6, en los adenocarcinomas son significativos. Sin embargo, estos resultados nos indican una mayor expresión de todas las formas existentes de KLF6, la forma salvaje y las formas de procesamiento alternativo descritas para su ARN mensajero (V1, V2 y V3) (Narla et al., 2005 a; Yea et al., 2008). KLF6-SV1 y SV2 se localizan en el citoplasma y antagonizan la actividad transcripcional de KLF6. Se ha demostrado que KLF6-SV1 induce la apoptosis espontánea en las células de cáncer de próstata. Por otra parte, los altos niveles de expresión KLF6-SV1 en el tumor de próstata se asocia con una baja tasa de supervivencia (Narla et al., 2008). También, se han publicado antecedentes que demuestran que KLF6-SV1 es un importante regulador del crecimiento, migración, invasión y supervivencia de las células de cáncer gástrico, y la desregulación de KLF6-SV1 por ARN de silenciamiento (o small interfering RNA) puede ofrecer un nuevo enfoque frente a una terapia génica para este tipo de cáncer gástrico (Chen et al., 2011). Fue necesario realizar estudios de RT-PCR a partir del ARN mensajero de los diferentes tumores, para poder analizar si el aumento en la expresión de KLF6 se debe exclusivamente a su forma salvaje o las isoformas de procesamiento alternativo. Las RTPCR revelaron la predominancia de forma salvaje de KLF6 en epitelio normal de colon. No obstante, esta situación cambió al analizar los adenocarcinomas ya que se observó la aparición progresiva de las formas de procesado alternativo, lo que ocasionó un aumento en la cantidad del amplificado total (salvaje+variantes) con respecto al salvaje, como ocurría en el estadio T1.

En el estadio T2 se observó un aumento en la expresión de KLF6, al tiempo que aparecieron bandas de menor tamaño del esperado para el amplicón total. Probablemente, estos resultados de la aparición de nuevas formas aberrantes, se deba a la presencia de delecciones, que no se ajustan a las formas de procesamiento alternativo descritas por Narla et al., (2005 a,b). Lo más destacado de este estudio, fue que en el estadio de mayor malignidad (T3), se observó una predominancia total de las formas de procesado alternativo ya que no se obtuvo la amplificación de la forma salvaje de KLF6. Estos resultados coinciden con lo observado en cáncer de próstata (Narla et al., 2005 a,b) y en el 2008 se publicó que habían observado la sobre expresión de KLF6-SV1, formas de procesado alternativo a medida que aumenta el proceso de malignización (Narla et al. 2008). Además, Difeo
(2008) describe que el aumento de la expresión de KLF\&SV1 está asociado a una baja supervivencia en pacientes con adenocarcinomas de pulmón.

Sin embargo, los datos obtenidos, tanto a nivel de ARN mensajero como de proteína, sugieren que las variantes de KLF6 poseen una función antagonista a la capacidad que posee la forma salvaje de KLF6 de actuar como supresor tumoral in vivo. En este sentido, el incremento en la generación de formas de procesamiento alternativo de KLF6, podría contribuir a que las células adquieran un fenotipo tumorogénico, independientemente de si se produce pérdida alélica, mutaciones somáticas inactivantes o metilación de promotor, probablemente mediante una actividad dominante-negativa sobre la función de la proteína salvaje.

El posible papel que puedan tener las alteraciones del mecanismo de procesamiento alternativo, se está observando en un amplio rango de enfermedades humanas (Orengo \& Cooper 2007), especialmente en cáncer (Venables et al., 2006) y canceres de mama (Venables et al., 2008). En general, la desregulación del procesamiento alternativo de numerosos genes y la subsiguiente generación de diferentes transcritos, refleja algún fallo en el mecanismo deregulación de este proceso (incluidos genes que lo regulan), por lo tanto podría tener un papel, en la progresión del cáncer de colon. Así mismo, está demostrado que el incremento de la expresión de KLF6-SV1, en tumores de próstata predice una baja supervivencia y los perfiles de recurrencia tumoral (Chen et al., 2011). Además estos estudios permitirían predecir el comportamiento metastásico del tumor, por lo que KLF-SV1 puede representar una nueva diana terapéutica (Nagai et al., 2009). Otros estudios, revelan que la reducción de la expresión de KLF6-SV2 en las muestras de cáncer hepatocelular, describen una función anti-proliferativo y pro-apoptóticos (Hanoun et al., 2010). Basándonos en estos hallazgos postulamos que estas formas de procesamiento que se inducen y sobre expresan durante el proceso de tumorogénesis colorrectal, más que ser un simple producto resultado del cáncer, están implicados en promover la tumorogénesis. Además, la localización subcelular de KLF6 en las células epiteliales fue sólo citoplásmica en los estadios más avanzados de los adenocarcinomas. Los resultados de la PCR revelaron que durante la progresión tumoral se produce un incremento en la aparición de otras formas de procesado alternativo de KLF6, llegando a desaparecer su forma salvaje en el estadio T3 de los adenocarcinomas. Es por ello que se plantea a KLF6 como un marcador para el diagnóstico precoz de CCR.

La Figuras 10 A y B representan la cuantificación en detalle de las diversas formas de procesado total y de la forma salvaje de KLF6 a partir de 7 muestras de tumores en 
estadio T2. Como se puede observar, en la mayoría de estas muestras la expresión de las formas alternativas es mayor a la forma normal, tal y como se deduce del cociente entre formas salvajes/formas totales, que posee un valor menor de 0.5 en 5 de los 7 tumores analizados.

En general, estos resultados corroboran los obtenidos en los ensayos de inmunohistoquímica, en los que se observó un aumento progresivo de la expresión de KLF6 a medida que avanza el proceso de malignización tumoral (Figs. 7 AF). En este caso, si bien las PCRs no son cuantitativas, si podemos ver un aumento en la intensidad de la señal de los amplicones de KLF6. Sin embargo, lo que es más significativo, es el cambio en la aparición de KLF6-SV1. Desde la expresión del mensajero normal de KLF6 en epitelio sano, hasta la aparición predominante de formas de procesamiento alternativo en el caso de muestras de CCR. Según, Sangodkar (2009) corresponden a un aumento de expresión KLF6-SV1, asociada a mal pronóstico en cáncer gástrico.
Con todo estos antecedentes, podemos concluir que el análisis de KLF6, tanto el de su forma salvaje como el de las isoformas, y en base a su implicación directa en la progresión del CCR, podría ser un excelente marcador para el diagnóstico precoz de CCR, sobre todo a la hora de pesquisar el estado o etapa de la enfermedad. De esta forma poder determinar estado precoz del cáncer de colon.

\section{AGRADECIMIENTOS}

Este trabajo fue financiado por: Universidad de Tarapacá, Departamento de Biología "Proyecto Mayor Código 1042, Arica, Chile; Universidad Autónoma de Madrid, Facultad de Ciencias, Depto. de Citología y Facultad de Medicina; y Hospital Central de la Defensa Gómez-Ulla, Servicio de Anatomía Patológica de Madrid, España.

LAIME, D.; LLANQUI, O.; SANZ.RODRÍGUEZ, F.; JUARRANZ, A.; BOTELLA, M. L. \& RAMÍREZ-GARCÍA, J. R. Role of KLF6 as early predictor in human colorectal cancer. Int. J. Morphol., 30(3):1115-1131, 2012.

SUMMARY: Colorectal cancer (CRC) is the second most common type of cancer in the European population. Currently there molecular biomarkers that can be used for early detection of cancer of CRC. Is a tumor suppressor KLF6 associated with several types of cancers. Our hypothesis is that KLF6 can be an excellent marker for the early diagnosis of CRC. To study the implication of KLF6 in CRC, we selected 15 biopsies of each stage (T1, T2 and T3) from the archives of the Pathology Department of Defense Central Hospital Gómez-Ulla, which had areas of affected tissue (tumor) and unaffected areas (non-tumor). This study was performed histological, immunohistochemical and RT-PCR, based on the expression of three genes, markers Ki67 and p53 as positive and as a marker in KLF6 study. The results showed that the expression of KLF6 is directly related to increased malignancy cell adenocarcinomas, corroborated by RT-PCR, showing the gradual emergence of alternative forms processing, corresponding to no KLF6. This protein was expressed both cytoplasmic and nuclear in the early stages T1 and T2, disappearing at the nuclear level in the most advanced stage (T3). KLF6 conclude that a good CRC tumor marker because it shows patterns of expression level increased cytoplasmic and nuclear level decreasing.

KEYWORDS: KLF6; Adenocarcinoma; Colon cancer.

\section{REFERENCIAS BIBLIOGRÁFICAS}

Bieker, J. J. Kruppel-like factors: three fingers in many pies. $J$. Biol. Chem., 276:34355-8, 2001.

Black, A. R.; Black, J. D. \& Azizkhan-Clifford, J. Sp1 and kruppellike factor family of transcription factors in cell growth regulation and cancer. J. Cell Physiol., 188:143-60, 2001.

Buendía, M. A.Tumour suppressors in hepatocellular carcinoma: many are called, but few are chosen. J. Hepatol., 46:546-8, 2007.

Chen, H.; Chen, L.; Sun, L.; Zhen, H.; Li, X. \& Zhang, Q. A small interfering RNA targeting the KLF6 splice variant, KLF6SV1, as gene therapy for gastric cancer. Gastric Cancer, 2011.

Chen, H. K.; Liu, X. Q.; Lin, J.; Chen, T. Y.; Feng, Q. S.; Zeng, Y. $\mathrm{X}$. Mutation analysis of KLF6 gene in human nasopharyngeal carcinomas. Ai. Zheng., 21:1047-50, 2002.
Cho, Y. G.; Choi, B. J.; Kim, C. J.; Song, J. W.; Kim, S. Y.; Nam, S. W.; Lee, S. H.; Yoo, N. J.; Lee, J. Y. \& Park, W. S. Genetic alterations of the KLF6 gene in colorectal cancers. APMIS, 14:458-64, 2006.

DiFeo, A.; Feld, L.; Rodriguez, E.; Wang, C.; Beer, D. G.; Martignetti, J. A. \& Narla, G. A functional role for KLF6SV1 in lung adenocarcinoma prognosis and chemotherapy response. Cancer Res., 15;68(4):965-70, 2008.

DiFeo, A.; Narla, G.; Camacho-Vanegas, O.; Nishio, H.; Rose, S. L.; Buller, R. E.; Friedman, S. L.; Walsh, M. J. \& Martignetti, J. A. E-cadherin is a novel transcriptional target of the KLF6 tumor suppressor. Oncogene, 25:6026-31, 2006.

Ghaleb Amr M. \& Yang Vincent, W. The Pathobiology of Krüppellike Factors in Colorectal Cancer. Curr. Colorectal Cancer Rep., 4(2):59-64, 2008. 
Glinsky, G. V.; Glinskii, A. B.; Stephenson, A. J.; Hoffman, R. M. \&Gerald, W. L. Gene expression profiling predicts clinical outcome of prostate cancer. J. Clin. Investigation, 113(6):913-23, 2004.

Hanoun, N.; Bureau, C.; Diab, T.; Gayet, O.; Dusetti, N.; Selves, J.; Vinel, J. P.; Buscail, L.; Cordelier, P. \& Torrisani, J. The SV2 variant of KLF6 is down-regulated in hepatocellular carcinoma and displays anti-proliferative and pro-apoptotic function. J. Hepatology, 53:880-8, 2010.

Haber, D. \& Harlow, E. Tumour-suppressor genes: evolving definitions in the genomic age. Nature Genetics, 16: 320-2, 1997.

Hsu Su-Ming; Raine, L. \& Fanger, H. Use of Avidin-BiotinPeroxidase Complex (ABC) in Immunoperoxidase Techniques: A Comparison between ABC and Unlabeled Antibody (PAP) Procedures. J. Histochem. . Cytochem., 29(4):577-80, 1981.

Ito, G.; Uchiyama, M.; Kondo, M.; Mori, S.; Usami, N.; Maeda, O.; Kawabe, T.; Hasegawa, Y.; Shimokata, K. \& Sekido, Y. Kruppel-like factor 6 is frequently down-regulated and induces apoptosis in non-small cell lung cancer cells. Cancer Res., 64:3838-43, 2004.

Kettunen, E.; Anttila, S.; Seppänen, J. K.; Karjalainen, A.; Edgren, H.; Lindström, I.; Salovaara, R.; Nissén, A. M.; Salo, J.; Mattson, K.; Hollmén, J.; Knuutila, S. \& Wikman, H. Differentially expressed genes in nonsmall cell lung cancer: expression profiling of cancer-related genes in squamous cell lung cancer. Cancer Genetic Cytogenet., 149(2):98-106, 2004.

Kremer-Tal, S.; Reeves, H. L.; Narla, G.; Thung, S. N.; Schwartz, M.; Difeo, A.; Katz, A.; Bruix, J.; BioulacSage, P.; Martignetti, J. A. \& Friedman, S. L. Frequent inactivation of the tumor suppressor Kruppel-like factor 6 (KLF6) in hepatocellular carcinoma. Hepatology, 40:1047-52, 2004.

Kremer-Tal, S.; Narla, G.; Chen, Y.; Hod, E.; DiFeo, A.; Yea, S.; Lee, J. S.; Schwartz, M.; Thung, S. N.; Fiel, I. M.; Banck, M.; Zimran, E.; Thorgeirsson, S. S.; Mazzaferro, V.; Bruix, J.; Martignetti, J. A.; Llovet, J. M. \& Friedman, S. L. Downregulation of KLF6 is an early event in hepatocarcinogenesis, and stimulates proliferation while reducing differentiation. J. Hepatol., 46 645-54, 2007.

López-Abente, G.; Ardanaz, E.; Torrella-Ramos, A.; Mateos, A.; Delgado-Sanz, C. \& Chirlaque, M. D. for the Colorectal Cancer Working Group. Changes in colorectal cancer incidence and mortality trends in Spain. Annals of Oncology. (Supplement 3):76-82, 2010.

Nagai, R.; Friedman, S. L. \& Kasuga M., The Biology of Krüppellike Factors, Springer 2009.
Narla, G..; DiFeo, A.; Fernandez, Y.; Dhanasekaran, S.; Huang, F.; Sangodkar, J.; Hod, E.; Leake, D.; Friedman, S. L.; Hall, S. J.; Chinnaiyan, A. M.; Gerald, W. L.; Rubin, M. A. \& Martignetti, J. A. KLF6-SV1 overexpression accelerates human and mouse prostate cancer progression and metastasis. Clin. Invest. 118:2711-21, 2008.

Narla, G.; DiFeo, A.; Reeves, H. L.; Schaid, D. J.; Hirshfeld, J.; Hod, E.; Katz, A.; Isaacs, W. B.; Hebbring, S.; Komiya, A.; McDonnell, S. K.; Wiley, K. E.; Jacobsen, S. J.; Isaacs, S. D.; Walsh, P. C.; Zheng, S. L.; Chang, B. L.; Friedrichsen, D. M.; Stanford, J. L.; Ostrander, E. A.; Chinnaiyan, A. M.; Rubin, M. A.; Xu, J.; Thibodeau, S. N.; Friedman, S. L. \& Martignetti, J. A. A germline DNA polymorphism enhances alternative splicing of the KLF6 tumor suppressor gene and is associated with increased prostate cancer risk. Cancer Res., 65:1213-22, 2005a.

Narla, G.; DiFeo, A.; Yao, S.; Banno, A.;, Hod, E.; Reeves, H. L.; Qiao, R. F.; Camacho-Vanegas, O.; Levine, A.; Kirschenbaum, A.; Chan, A. M.; Friedman, S. L.; Martignetti, J. A. Targeted inhibition of the KLF6 splice variant, KLF6 SV1, suppresses prostate cancer cell growth and spread. Cancer Res., 65:5761$8,2005 b$.

Narla, G.; Heath, K. E.; Reeves, H. L.; Li, D.; Giono, L. E.; Kimmelman, A. C.; Glucksman, M. J.; Narla, J.; Eng, F. J.; Chan, A. M.; Ferrari, A. C.; Martignetti, J. A. \& Friedman, S. L. KLF6, a candidate tumor suppressor gene mutated in prostate cancer. Science, 294:2563-6, 2001.

Narla, G.; Kremer-Tal, S.; Matsumoto, N.; Zhao, X.; Yao, S.; Kelle, K.; Tarocchi, M. \& Friedman, S. L. In vivo regulation of p21 by the Kruppel-like factor 6 tumor-suppressor gene in mouse liver and human hepatocellular carcinomaIn vivo regulation of p21 by KLF6. Oncogene, 26:4428-34, 2007.

Orengo, J. P. \& Cooper, T. A. Alternative splicing in disease. $A d v$. Exp. Med. Biol., 623:212-23, 2007.

PAHO Plan of Action for Cancer Prevention \& Control: Cancer Stakeholders Meeting. (Washington, DC) Cancer in Latin America and the Caribean, 2008.

Reeves, H. L.; Narla, G.; Ogunbiyi, O.; Haq, A. I.; Katz, A.; Benzeno, S.; Hod, E.; Harpaz, N.; Goldberg, S.; Tal-Kremer, S.; Eng, F. J.; Arthur, M. J.; Martignetti, J. A. \& Friedman, S. L. Kruppel-like factor 6 (KLF6) is a tumor-suppressor gene frequently inactivated in colorectal cancer. Gastroenterology, 126:1090-103, 2004.

Valey, J. M.; Attwooll, C.; White, G.; Thorncroft, M.; Kelsey, A. M.; Greaves, M.; Boyle, J. \& Birch, J. M. Characterization of germline TP53 splicing mutation and their genetic and functional analysis. Oncogene, 20: 2647-54, 2001.

Venables, J. P. Aberrant and alternative splicing in cancer. Cancer Res., 64:7647-54, 2004. 
Venables, J. P. Unbalanced alternative splicing and its significance in cancer. Bioessays, 28(4):378-86, 2006.

Venables, J. P.; Klinck, R.; Bramard, A.; Inkel, L.; Dufresne-Martin, G.; Koh, C.; Gervais-Bird, J.; Lapointe, E.; Froehlich, U.; Durand, M.; Gendron, D.; Brosseau, J. P.; Thibault, P.; Lucier, J. F.; Tremblay, K.; Prinos, P.; Wellinger, R. J.; Chabot, B.; Rancourt, C. \& Elela, S. A. Identification of alternative splicing markers for breast cancer. Cancer Res., 68(22):9525-31, 2008.

Watanabea, K.; Shin, O.; Ichiro, M. Ryozo N. \& Takashi, Kadowakid. KLF6 in Nonalcoholic Fatty Liver Disease: Role of Fibrogenesis and Carcinogenesis, Gastroenterology, 135(1):309-12, 2008.

Xian-Feng; Cheng; Di Li; Min Zhuang; Zhao-Yan, Chen \& DeXiang, Lu. Growth Inhibitory Effect of Krüppell-Like Factor 6 on human Prostatic carcinoma and renal carcinoma cell Lines. Tohoku J. Exp. Med., 216:35-45, 2008.

Yamashita, K.; Upadhyay, S.; Osada, M.; Hoque, M. O.; Xiao, Y.; Mori, M.; Sato, F.; Meltzer, S. J. \& Sidransky, D. Pharmacologic unmasking of epigenetically silenced tumor suppressor genes in esophageal squamous cell carcinoma. Cancer Cell., 2:485-495, 2002.

Yea, S.; Narla, G.; Zhao, X.; Garg, R.; Tal-Kremer, S.; Hod, E.; Villanueva, A.; Loke, J.; Tarocchi, M.; Akita, K.; Shirasawa, S.; Sasazuki, T.; Martignetti, J. A.; Llovet, J. M. \& Scott Friedman, L. Ras Promotes Growth by Alternative SplicingMediated Inactivation of the KLF6 Tumor Suppressor in Hepatocellular Carcinoma. Gastroenterology, 134(5):1521-31, 2008.

\author{
Dirección de correspondencia: \\ Dra. Delia I. Laime C. \\ Departamento de Biología. \\ Facultad de Ciencias \\ Universidad de Tarapacá. \\ Avenida: General Velásquez 1775, Casilla 7-D, Arica \\ CHILE \\ Teléfono: (56) (58) 205365 \\ Fax: (56) (58) 205381. \\ Email: dlaime@uta.cl
}

Recibido : 13-04-2012

Aceptado: 25-07-2012 